\title{
Ordenando no Tempo e no Espaço: Epistemologia Narrativa, Semiologia e Raciocínio Clínico
}

\author{
Ordering in Time and in Space: Narrative \\ Epistemology, Semiology and Clinical \\ Reasoning
}

\author{
Leda Amar de Aquino \\ Susana Maciel Wuillaume ${ }^{I I}$ \\ Maria Helena Cabral de Almeida Cardoso ${ }^{I I}$
}

\section{PALAVRAS-CHAVE \\ - Sinais e Sintomas. \\ - Competência Clínica. \\ - Narração.}

\section{KEYWORDS}

- Signs and Syntoms.

- Clinical Competence.

- Narration.

Recebido em: 24/08/2011

Aprovado em: 30/12/2011

REVISTA BRASLLEIRA DE EDUCAÇÃO MÉDICA
${ }^{I}$ Ministério da Saúde. Instituto Nacional do Câncer,Brasília, DF, Brasil.

"I Instituto Nacional de Saúde da Mulher, da Criança e do Adolescente, Rio de Janeiro, RJ, Brasil. 


\section{INTRODUÇÃO}

Embora o senso comum tente aproximar a medicina do modelo de neutralidade preconizado pela ciência, para chegar à doença, o médico, em sua prática clínica, recorre a meios indiretos e se depara com a subjetividade implícita em suas interpretações, julgamentos e tomadas de decisão ${ }^{1}$. A partir das histórias que compõem as narrativas dos pacientes (a anamnese) e da observação e anotação de sinais de adoecimento em seus corpos (o exame físico) é que os médicos interpretam e criam a própria narrativa médica. A esse método de investigação damos a denominação de Semiologia Médica, base do raciocínio clínico e elemento fundamental ao diagnóstico.

A importância da Semiologia Médica vem interessando à mídia, sobretudo no que se refere à narrativa médica, sublinhando notadamente a do paciente sobre sua doença e a do médico sobre a doença dele. Há uma proliferação de veículos de divulgação populares, como jornais ${ }^{2}$, revistas ${ }^{3}$ e programas de $\mathrm{TV}^{4}$, voltados especificamente para a dramatização e a informação sobre as mais variadas formas de narrar o adoecimento, a recuperação e a luta por uma vida saudável. Por outro lado, no campo da própria medicina, a cada dia se afirma, em oposição à crença inabalável no aparato tecnológico, a necessidade de escutar a história do paciente como ponto de partida para todo e qualquer exercício de diagnose e eficácia terapêutica.

Nesse sentido, vêm sendo desenvolvidas diversas iniciativas voltadas ao aperfeiçoamento do pensar narrativamente de médicos. Além de programas de pesquisa e cursos espalhados por variadas universidades mundo afora - como os de Columbia, Duke e Vanderbilt, nos Estados Unidos, e da Universidade de Navarra, na Espanha -, são frequentes os simpósios e congressos que tratam do tema. Por exemplo, em setembro de 2010, a Faculdade de Letras da Universidade de Lisboa organizou o Colóquio Internacional Narrativa e Medicina: Doença e Diálogo, cujo objetivo era conjugar as disciplinas da Medicina, da Literatura e da Filosofia para explanar como a narrativa poderia contribuir para a melhoria das relações entre doentes, médicos e outros profissionais da saúde. Emblematicamente, tinha como professores convidados próceres da literatura portuguesa, como João Lobo Antunes, bioeticistas e filósofos da medicina, como Richard Zaner, e médicas, como Rita Charon ${ }^{5}$.

O nascimento das bases da Semiologia Médica é bem antigo e remonta à época em que Hipócrates e seus discípulos sistematizaram o método clínico, dando à história dos sintomas verbalizados pelo doente e ao exame físico uma importância que discursivamente se assemelha à definição da medicina como ciência e arte ainda imperante nos dias de hoje $\mathrm{e}^{6}$.
Mudanças e rupturas importantes se fizeram presentes ao longo do tempo. Seguindo Canguilhem ${ }^{7}$, pode-se afirmar que a medicina ocidental contemporânea e sua semiologia transitam numa zona de dissociação entre o paciente e sua enfermidade, caracterizando o primeiro pela segunda, implicando menor valoração do conjunto dos sintomas espontaneamente relatados/apresentados pelo doente.

No espaço e tempo dessa realidade, Camargo Jr. ${ }^{8}$ ilustra bem essa dissociação, dentro da própria Semiologia, quando se refere ao fato de que, atualmente, o exame físico envolve uma semiologia "armada" (p. 191) e uma semiologia "desarmada" (p. 191). A primeira seria a que faz uso dos exames complementares, variada e complexa, remetendo à noção de medicina como "ciência concretizada" (p. 191), respaldada na verdade objetiva, em que pese a necessidade evidente da interpretação dos resultados obtidos. A semiologia "desarmada" seria a que depende do próprio médico, que faz uso da visão, da audição, do olfato e das mãos para observar, ouvir, inspecionar, palpar, percutir e auscultar o paciente, utilizando instrumentos simples como o estetoscópio, o termômetro, o esfigmomanômetro, dentre outros. A primeira vem crescendo em importância e ameaçando tornar a segunda uma "arte" perdida.

Entretanto, nem uma, nem outra podem possibilitar o entendimento do complexo processo de adoecimento e a formalização das hipóteses diagnósticas. Para ultrapassar a zona cinzenta da dissociação, o profissional atuante na área biomédica, tal como todos os seres humanos, se relaciona com os outros e consigo mesmo, e, nesse processo, ordena os "acontecimentos" no tempo e no espaço, gerando ligações consequentes ou não entre eles. Trata-se de entender, como Carr', que o ato de narrar está presente em todos os níveis e é condição intrínseca do viver do homem.

A partir desse reconhecimento, compreendemos, tal como Epstein $^{10}$, que há na base do conhecimento biomédico, mesmo na sua vertente de ciência, uma "epistemologia narrativa" (p. 31 ), na medida em que ele se volta para decifrar pistas, sinais, sejam interiorizados nas moléculas, presentes na superfície dos corpos ou expressos como sintomas experimentados pelo doente.

As etapas do atendimento médico são definidas numa sequência temporal: anamnese, exame físico, exames complementares e, finalmente, a formulação do diagnóstico. As interpretações se dão através do relato retrospectivo, coerente, cuidadoso e cronologicamente ordenado, desvelando a doença no corpo do paciente. É a organização narrativa que propicia a articulação entre os elementos-chave obtidos pela Semiologia e o saber médico. Como não poderia deixar de ser, essa narra- 
tologia reflexiva traz consigo a subjetividade autoral, no momento em que é o médico quem decide, seleciona e organiza o material, no intuito de torná-lo inteligível e coerente ${ }^{11}$.

O método clínico não pode ser totalmente explicado em bases racionais e científicas. A escolha dos elementos-chave que servirão para orientar o raciocínio clínico na formulação de hipóteses diagnósticas, da forma como se processa, não é passível de sistematização numa lei geral. Isto porque essa seleção e interpretação de "pistas" vão depender não só do conhecimento técnico/científico do médico, mas de sua "experiência pessoal/profissional", que alguns chamam de "intuição" ou "bom senso", mas que na verdade é um "olhar" que abrange vários níveis de informações, que mistura tipos de saber distintos, embora não excludentes. Castiel ${ }^{12}$ e Montgomery ${ }^{13}$ chamam isso de sabedoria prática ou phronesis. $\mathrm{O}$ exercício da Semiologia está fortemente entrelaçado a uma experiência clínica sólida, resultante do acúmulo de casos clínicos vivenciados ${ }^{13}$. Na prática, o médico se depara com a individualidade e a particularidade de cada caso, porque, embora a doença seja definida e classificada em compêndios de Medicina, a resposta humana a esse evento não é a mesma em todos os indivíduos. E a singularidade de cada caso vem à tona através da narrativa médica. $\mathrm{O}$ fato de os profissionais médicos terem sido submetidos a uma educação científica e tecnológica não altera em nada a estrutura narrativa de seu conhecimento $^{14}$.

Montgomery ${ }^{13}$ refere que a educação médica ignora a tensão/contradição existente entre a teoria da clínica e a "phronesiologia" da medicina, ou seja, entre o saber e o fazer. E que a incerteza e o cunho circunstancial da prática nunca são explicitados aos futuros profissionais, mesmo sendo o gerenciamento da incerteza, em todas as suas variedades, o foco central (jamais declarado) da educação clínica. E acrescenta que a educação médica voltada para a prática clínica faz com que os estudantes de Medicina construam profissionalmente relatos narrativos do que observam e aprendam quais achados devem incluir e quais excluir, de modo a impulsionar o raciocínio clínico. Porém, sublinha que, nesse momento, a prática não serve apenas para a aquisição de experiência e habilidades, mas também contém uma parte implícita da educação moral da profissão, onde os "rituais" inculcam e reforçam atitudes e comportamentos centrais para a "boa prática".

Esse artigo tem como objetivo discutir o papel adstrito à narrativa médica, articulando-a aos procedimentos semiológicos e à construção do raciocínio clínico. A discussão acerca do papel da narratologia na construção do conhecimento médico, levada a cabo por diversos autores e discutida em suas variadas aplicações ${ }^{15}$, foi o ponto de partida para a hipótese heurís- tica condutora da investigação realizada, isto é, a de que não há consciência por parte dos médicos da base epistemológica da narrativa, levando-os a relacioná-la apenas àquelas que escutam de seus pacientes e às que fazem sobre eles.

\section{PERCURSO METODOLÓGICO}

O estudo foi realizado com residentes de Pediatria que estavam terminando a residência médica (R2) no Hospital Municipal Jesus e no Instituto Nacional de Saúde da Mulher, da Criança e do Adolescente - Fernandes Figueira, da Fundação Oswaldo Cruz (INSMCA-IFF/Fiocruz). Ambas as instituições são consideradas centros de referência em cuidados pediátricos, sendo o primeiro uma unidade de assistência geral, e o segundo voltado para assistência secundária e terciária. Ambos possuem estrutura física e recursos humanos capacitados a prestar tais cuidados em todos os níveis.

A amostra foi de conveniência ${ }^{16}$, em função da facilidade de acesso da primeira autora a ambas as instituições: na primeira, atuou como pediatra de 1976 a 2000; na segunda, foi parceira em diversos projetos institucionais.

De modo algum pretendemos fazer uma análise comparativa, partindo de cenários de cuidados diferenciados, uma vez que nossa principal questão remete ao entendimento ou não de uma epistemologia narrativa embutida tanto no processo de diagnóstico quanto no tratamento a ser proposto, incluindo, é claro, a adesão terapêutica. Seja diante de doentes com enfermidades complexas (caso do INSCM-IFF/Fiocruz), seja diante daqueles mais vinculados à pediatria geral, para efeitos metodológicos, assumiu-se a questão da narratividade como intrínseca ao desenvolvimento do raciocínio clínico em quaisquer níveis de assistência. Nesse sentido, definimos raciocínio clínico como um dos componentes essenciais à competência profissional dos médicos e que usualmente também é chamado de julgamento clínico, significando a tomada de decisões clínicas ou a solução dos problemas clínicos ${ }^{17}$. Basicamente, isso quer dizer julgar sobre a incerteza no decorrer do cuidar do paciente ou o caminho cognitivo percorrido pelo médico para atingir esse objetivo ${ }^{18}$.

$\mathrm{O}$ único critério de inclusão foi o de estar terminando o segundo ano do Programa de Residência Médica em Pediatria (R2). Optou-se por tal recorte porque, em termos de formação, o término da residência corresponde ao ápice de três momentos distintos: o primeiro, relativo à introdução ao saber biomédico por meio dos manuais didáticos e das aulas professorais na graduação; o segundo, quando, ainda na condição de aluno universitário, ocorre o primeiro contato com os pacientes; e, por fim, o terceiro, quando, já portando o diploma de médico, completa-se a residência, uma forma mista de aprendizado 
e trabalho, juntando teoria e prática, na qual o exercício do ofício se faz presente e onde o raciocínio clínico, como competência fundamental, é insistentemente mais desenvolvido e trabalhado.

Ao todo, realizamos 17 entrevistas, durante os meses de janeiro e fevereiro de 2010, oito delas com residentes do INSCM-IFF/Fiocruz e nove no Hospital Municipal Jesus, englobando todos aqueles que cumpriam o critério de inclusão.

A técnica empregada foi a da entrevista semiestruturada, entendida como uma conversa dotada de finalidade que mistura perguntas abertas e fechadas ${ }^{19}$. Para isto foi elaborado um roteiro-guia baseado em pesquisa bibliográfica de cunho teórico e conceitual. Tal roteiro centrou-se em questões amplas envolvendo a Semiologia e, dentro dela, mais especificamente, o soerguimento de hipóteses diagnósticas, assim como o papel da narrativa no conhecimento médico, abarcando, dentre outros tópicos, a anamnese, a construção e evolução do caso clínico, a percepção prognóstica e a ordenação dos dados no acompanhamento do paciente.

Os depoimentos foram gravados e transcritos. Para efeito de análise, a transcrição foi literal. Todavia, para fins expositivos, procedeu-se a ligeira revisão, mormente de pontuação, para tornar a linguagem oral mais inteligível a nossos leitores. Manteve-se o anonimato utilizando-se siglas acompanhadas de números que obedeceram à ordem de realização das entrevistas.

A técnica aplicada à leitura do discurso compreendeu quatro etapas. Na primeira, realizada no próprio momento da entrevista, buscaram-se as percepções-chave claramente veiculadas pela fala e relacionadas aos tópicos selecionados, anotando-as num diário; na segunda, correspondente ao momento da transcrição, consideraram-se tais anotações e atentou-se mais sistematicamente para as caracterizações comuns; na terceira, empreendida sobre o material transcrito literalmente, processou-se uma codificação aberta e outra fechada, sendo que a primeira se voltou para captar as variações e exceções às categorias de interesse relativas à narrativa médica presentes nos procedimentos semiológicos e de formação do raciocínio clínico, e a segunda especificamente englobando essas categorias; na quarta leitura, finalmente, procedeu-se ao entrecruzamento vertical e horizontal entre as categorias resultantes do processo codificador, chegando-se a duas temáticas-chave: (i) narrativa e semiologia médica e (ii) narrativa e desenvolvimento do raciocínio clínico.

O projeto foi aprovado em 09/09/2009 pelo Comitê de Ética em Pesquisa em seres humanos do INSCMA-IFF/Fiocruz CAAE n 0069.0.008.000-09 e da Secretaria Municipal de Saúde e Defesa Civil do Rio de Janeiro/Hospital Municipal
Jesus CAAE n 0268.0.314.000-09. Foram solicitados consentimentos livres e informados de todos os residentes que participaram da pesquisa.

\section{RESULTADOS E DISCUSSÃO}

Devido ao cunho qualitativo da pesquisa, escolhemos apresentar cada um dos temas resultantes de nossa pesquisa imbricados à discussão sobre eles. Os trechos de entrevistas foram reproduzidos no sentido de ilustrar, corroborar e mesmo servir de fundamento à argumentação.

A escolha de usar uma amostra de conveniência significa que os resultados obtidos se referem ao grupo de entrevistados, não podendo, portanto, ser extrapolados. Por outro lado, o fato de essa amostra compreender R2s em Pediatria significa, no que tange à semiologia e ao raciocínio clínico, que as narrativas neles empreendidas possuem características diferenciadas, principalmente quando estão em pauta pacientes ainda incapazes de contar a história de sua saúde ou de sua enfermidade. Há aquela que os pequenos corpos com seus sinais e sintomas contam; há a dos pais ou responsáveis sobre o estar saudável e/ou o adoecer de suas crianças e, por fim, há a dos próprios médicos ao se apossarem das duas primeiras, do estoque de narrativas trazidas pelo saber médico contido nas publicações científicas que leem, somado à composta pelos exames complementares que, em seu conjunto, formam a deles próprios, cujo enredo é a saúde ou a doença de seus pacientes.

\section{Semiologia Médica e Narrativa: Teoria e Prática}

Segundo Romeiro ${ }^{20}$, um dos mais conhecidos e respeitados autores brasileiros sobre o assunto, Semiologia ou Semiótica é o tratado dos métodos de exame clínico, que compreende a semiotécnica (técnica da pesquisa dos sinais e sintomas), a semiogênese (busca as explicações fisiopatológicas que originaram os sinais e sintomas) e a clínica propedêutica (que procederá à análise crítica dos dados recolhidos para a formulação do diagnóstico ou hipóteses diagnósticas). Portanto, a Semiologia Médica é essencialmente prática, agilizada no contato direto com o paciente, e o ponto de partida da experiência clínica. O raciocínio clínico necessário à formulação das hipóteses diagnósticas não pode prescindir da Semiologia. Poderíamos, então, resumir Semiologia como um conjunto de ações ordenadas a serem executadas pelo médico a fim de concluir de modo mais seguro o diagnóstico do paciente, oferecer o tratamento devido e assegurar a adesão a ele.

Em nossa pesquisa, unânime e espontaneamente, os entrevistados relembraram o contato inicial com a Semiologia reportando momentos diversos, porém todos ainda no tem- 
po em que eram graduandos. A memória, sem exceções, está marcada por ser o primeiro encontro com o paciente, assim como por se vincular ao início de uma nova aprendizagem que os levaria, como descrevem, à prática da investigação clínica. Para E5, foi "a partir do terceiro ano", deixando claro que "o melhor da graduação foi o contato com o paciente." Já E14 se reporta ao mesmo período, mas faz questão de enfatizar que, além de ter sido o instante da proximidade com os pacientes, tudo "começou com a anamnese". E9, por sua vez, situa o encontro no quinto período após o básico, quando começaram as aulas e em seguida se deu a entrada no hospital, propiciando aos alunos "aprender a perguntar: o que perguntar, a deixar o paciente falar e a partir daí começar a investigar sua história". E17 remonta ao quarto período e sublinha toda a ação da equipe médica e de enfermagem nas enfermarias auxiliadas por monitores "bem aplicados, que levavam a gente até o paciente, mostravam como examinar, interagir e aprender a observar".

A grande variação no momento da inserção da Semiologia na grade curricular das escolas médicas, como também na carga horária total destinada a ela, e até mesmo as diferentes denominações recebidas - como Medicina Interna, Propedêutica, Clínica Médica - evidenciam as dificuldades de administrar proficuamente a transformação do estudante de Medicina num semiota, isto é, um bom identificador de sinais e sintomas ${ }^{21}$. Aliam-se também ao fato as diferenciadas opiniões sobre quais abordagens seriam as mais eficazes e que critérios deveriam ser comuns aos docentes para desenvolver conteúdos relacionados ao aprendizado da Semiologia ${ }^{21}$.

Nos trechos apresentados, entretanto, a par das variações de momento e de estratégias didáticas, sobressai a repetida insinuação do aprender uma ordenação de eventos explicitada pelas referências a "anamnese", "investigar a história" e "observar". Retrocedendo no tempo e no espaço, essas três noções sintetizam os princípios metódicos adotados por Hipócrates e seus discípulos para descrever cuidadosamente o conjunto de sintomas de modo a traçar um prognóstico da evolução do paciente, apoiando-se na opsis (observação) e na acö̈ (o que se ouve $)^{22}$. Aqui e agora, nossos entrevistados seguem basicamente a mesma trilha, em que pesem as mudanças, descontinuidades e rupturas ocorridas na construção do conhecimento médico. Para E13, por exemplo, simbolizando o posicionamento geral, a forma de exercer a medicina se consubstancia pelo treinar a escuta cuidadosa, pelo saber perguntar para evocar a recordação dos fatos e percepções do adoecer a serem narrados pelo paciente, ou seja, tudo se faz mais concreto, conforme afirma, com "a história completa, a anamnese, com todas as particularidades".
De novo, é a composição narrativa que emerge. Num certo sentido, o retorno da ênfase na escuta e no saber perguntar como forma de agenciamento da memória se transforma num meio de ultrapassar a dissociação constatada por Canguilhem ${ }^{7}$, à qual já nos referirmos, nos empurrando para a consciência, por parte de nossos entrevistados, da necessidade de deixar aflorar a espontaneidade como forma de aproximação e desvendamento de uma história que tanto para o médico quanto para o paciente gira em torno da saúde ou da doença. É a partir de um testemunho compartilhado, ou de uma história sobre a sintomatologia vivenciada pelo paciente, ouvida e observada pelo médico nos sinais encontrados nos corpos, que se dão os primeiros passos.

Todos os entrevistados fizeram referência ao treinamento para a realização do exame físico minucioso e detalhado de cada órgão e sistema, ainda na graduação, salientando que, todavia, na prática cotidiana, a Semiologia, descrita nos livros e tratados lidos, induz à ilusão de haver total sintonia entre teoria e prática. Já as situações vivenciadas no Programa de Residência Médica em Pediatria ensejaram constatar que, muitas vezes, teoria e prática se distanciaram, propiciando uma mudança do olhar, que se transforma finalmente, como diz E8, "no olhar clínico".

Camargo Jr. ${ }^{8}$, pesquisador e estudioso do conhecimento biomédico, reafirma a posição assumida por nossos entrevistados, sublinhando que "apesar de os manuais de Semiologia preconizarem um exame exaustivo, esquadrinhando cada parte do corpo, raramente isto ocorre na prática, sendo o procedimento bem mais sumário e orientado por hipóteses diagnósticas" (p. 192).

No entanto, mesmo com a excessiva importância que vem sendo dada aos recursos tecnológicos, ou seja, à semiologia "armada", também discutida por Camargo Jr. ${ }^{8}$, traduzida pelo uso indiscriminado de exames complementares, os entrevistados não deram relevância ao assunto, valorizando muito mais o encontro entre médico e paciente, o diálogo, a escuta como ferramentas fundamentais à construção da história do adoecer, complementada pelo exame físico minucioso. E11 exemplifica bem essa tomada de posição ao argumentar que "exame complementar, o nome já diz, é complementar".

A construção das narrativas médicas, que inclui os sinais captados e interpretados no exame físico, é fundamental para o raciocínio clínico, pois permitirá a contextualização do adoecer e a formalização de hipóteses diagnósticas. E12 sintetiza muito bem a noção externada por todos os entrevistados:

70\% a 80\% dos diagnósticos conseguem ser feitos só pela anamnese. [...] Outra palavra-chave é um bom exame físico. Não existe semiologia sem um bom exame físico. E sem semiologia não tem medicina. 
Foucault ${ }^{23}$, em sua seminal discussão sobre o nascimento da clínica moderna, embora não faça referência direta à epistemologia narrativa embutida no conhecimento médico, sinaliza que a clínica se consubstanciou quando, junto à concepção cronológica até então tradicional, passou a designar a doença como um conjunto de anormalidades, figuras, elementos destruídos ou modificados, unidos numa sequência de acordo com uma geografia que podia ser seguida passo a passo. Também, embora de forma não consciente e explicitada, para nossos entrevistados, a capacidade de ordenar mentalmente no tempo e no espaço o que ouviram na anamnese e observaram ao exame físico é que dá significado à Semiologia.

Cabe assinalar, todavia, que a narrativa, na acepção de todos, conjuga-se à ideia mais geral do "contar uma história", ligando-se à escuta do relato do paciente. E, dentro dessa moldura, é considerada elemento fulcral ao estabelecimento de uma boa relação do médico com seu paciente, porque é no processo de dialogar que a confiança se estabelece. Como afirma E10: "a anamnese vai sendo construída também no decorrer da confiança; quanto melhor a relação médico-paciente, melhor a anamnese". Ideia referendada por E9 quando diz que "depende do médico despertar a confiança para abordar determinadas questões: sexuais, número de parceiros, quem sustenta a casa, etc.".

Podemos, portanto, inferir que nossos entrevistados concordam com o papel da narrativa, sempre nomeada como anamnese ou história clínica, enquanto instrumental para o desenvolvimento da prática clínica e demonstram algum grau de concordância com a proposição de Favoreto e Camargo Jr. ${ }^{24}$ de que social e culturalmente o protagonismo do médico no processo terapêutico o faz responsável pela promoção do diálogo, de modo a propiciar que o paciente reflita e exponha sua narrativa pessoal sobre o adoecer. E isso, basicamente, implica a ampliação de seu "universo interpretativo" (s.p.) de modo a:

[...] capacitá-lo a reconhecer os contextos narrativos onde as falas, sentidos e demandas dos pacientes se inserem, tornando possível uma percepção e uma interpretação dos casos que transcendam o repertório biomédico ou a pura e simples coleta de dados sobre a doença (s.p.).

\section{Raciocínio Clínico e Narrativa - Caminhos do Pensamento}

A atividade médica tem como uma das finalidades principais chegar à melhor solução possível dos problemas clínicos apresentados pelos pacientes. A eficiência no processo de decisão diagnóstica e terapêutica é altamente dependente da capacidade do médico de analisar, sintetizar e interpretar adequadamente os dados clínicos obtidos através da Semiologia, como também de decidir sobre riscos e benefícios envolvendo testes diagnósticos e condutas terapêuticas.

Um dos modelos de raciocínio cuja aceitação é comum e geral na área da prática médica ainda hoje é o denominado hipotético-dedutivo, desenvolvido a partir das proposições de Popper $^{25}$ e muito difundido a partir da década de 1970. Atualmente, entretanto, no que diz respeito à clínica médica, vêm sendo desenvolvidas algumas reflexões no sentido de posicionar problemas que esta colocava diante da epistemologia popperiana. Um deles era o de que, enquanto modelo, ele não permitia encontrar muitas diferenças entre os profissionais experientes e os novatos. Tanto uns quanto outros seriam capazes de gerar numerosas hipóteses na mesma velocidade, constituindo-se como única diferença a constatação de os primeiros soerguerem melhores hipóteses, comprovada pelo fato de que a precisão diagnóstica das primeiras hipóteses geradas era um grande preditivo da conclusão final. E também eram muito mais capazes de selecionar as informações e fazer mais inferências a partir dos dados (anamnese e exame físico), apelando menos para o uso de disciplinas básicas, como a fisiopatologia. Tais constatações sugeriram a existência de uma forma de raciocínio vinculado à maior exposição a casos clínicos, isto é, uma experiência maior, que, de todo modo, ao enfrentar situações difíceis e ambíguas, requer recorrer às explicações fornecidas pelas chamadas ciências básicas ${ }^{17}$.

De todo modo, retornamos ao fato de que o médico, diante do paciente e de sua queixa, captando sinais e sintomas, formula hipóteses primárias, testadas por meio da anamnese, do exame físico e dos exames complementares, para chegar àquela mais correta. De modo semelhante à abordagem que detetives fazem para solucionar um crime, a hipótese diagnóstica vai sendo construída e reformulada, quando necessário, por meio de um processo de ordenamento espacial e temporal que não se faz evidente à consciência. É a partir de tal processo que o médico determina quais informações adicionais são necessárias relativas à história do paciente, ao exame físico e aos exames complementares para tomar uma decisão diagnóstica. Há uma abordagem sequencial de testagem de hipóteses. E, para tudo isso acontecer, é importante que o médico possua uma base de conhecimentos rica e extensa, guardada em sua memória, bem como experiência clínica, porque "no mundo real, as doenças e as síndromes variam mais em seus atributos constituintes que nas descrições típicas dos $\operatorname{livros}^{\prime 26}$ (p. 304). A experiência clínica aumenta a qualidade das hipóteses geradas.

Por isso, apesar do não reconhecimento da narratologia reflexiva que empreendem, todos os entrevistados asseveram que somente o contato com os pacientes e suas doenças, no 
cotidiano dos serviços médicos, permite desenvolver a experiência clínica. Entretanto, ao contrário de postularem um problema a partir de uma teoria, é pelo olhar, associado a uma sensação, que reconhecem o desenvolvimento do raciocínio clínico aplicado à evolução do estado patológico do paciente. E o espaço privilegiado para seu deslanchar, sem dúvida, é a residência médica. O trecho retirado da entrevista de E16 fala por si mesmo:

Eu OLHO e percebo quando um exame não está batendo. Como é isso? Um dia você percebe que você consegue ver. No início da residência você passa por uma criança e o estafe diz: "essa criança está esquisita" e a gente diz: "essa criança está dormindo". Quando você está terminando o seu R2, você diz: "essa criança está meio esquisita" e o R1 diz que ela está dormindo. Não é só olho. É um feeling, uma sensação. Você enxerga além do que você vê. (grifo nosso)

Por isso, ao estudar o papel da narrativa como essencial ao raciocínio clínico, Montgomery ${ }^{13}$ compara o processo de ensino-aprendizagem na medicina, metaforicamente, ao processo químico de "osmose", em que a experiência clínica vai se imiscuindo de tal forma que não há como voltar atrás. A sabedoria prática só é apreendida pela imersão, pela absorção, pela vivência do encontro médico-paciente. A autora se refere à experiência clínica como um estoque de vivências obtidas pelo médico por intermédio da habilidade de reunir, interpretar e sintetizar informações preliminares com observações cuidadosas, reconhecimento da anomalia e suas variações, condensando um saber que é ativado pelo encontro entre médico e paciente, através do olhar, do toque e do questionamento.

Muito embora o fantástico desenvolvimento tecnológico tenha proporcionado grandes avanços em relação à capacidade diagnóstica e à terapêutica, o "olhar" e o "feeling" referidos por E16, no fundo, remetem à aceitação de que os médicos trabalham em situação de incerteza. Assim sendo, o rigor absoluto do método clínico é uma idealização, pois na prática qualquer teoria sobre a doença se distancia do geral para se articular ao particular. Castiel ${ }^{12}$ refere que "mesmo um paciente confiável, com elementos semiológicos bem definidos, constitui virtualmente um campo de incertezas. Casos tendem a ser únicos, singulares". A necessidade humana de certeza obscurece a natureza circunstancial da medicina clínica.

Os médicos sempre estão pesquisando como decidir qual a melhor conduta a tomar em relação ao paciente numa situação em particular. A abundância de informações e de meios seguros para avaliá-las, conforme proposto, por exemplo, pela chamada Medicina Baseada em Evidências, reduz mas não eli- mina a incerteza. A educação médica continuada fornece grande quantidade de conhecimentos científicos, porém é o longo aprendizado clínico que prepara o médico para agir. Contudo, a junção profícua de ambos depende da ampliação da competência narrativa tão defendida por Charon ${ }^{27}$. Para a autora, esta competência é definida como um conjunto de habilidades capazes de considerar, internalizar, interpretar e ser motivado pelas histórias ouvidas e lidas (histórias dos pacientes e sua doença, relatos de casos clínicos, prontuários) e é ela que fornece os meios não só de compreensão do paciente, mas de entendimento da própria doença.

Os médicos devem aprender não somente o que fazer para tratar o paciente, mas o que fazer quando a informação é conflitante ou não disponível. Embora treinados para mirarem a certeza absoluta, exatamente porque o inesperado não pode ser excluído, também precisam estar abertos e conscientes em relação àquilo que foge aos tratados e às publicações científicas. Ser médico requer uma racionalidade prática, sempre remetida à phronesis, que Aristóteles descreveu como uma capacidade flexível, interpretativa, que permite aos pensadores morais - e aos médicos e aos navegadores, com os quais ele os compara determinar a melhor ação a tomar quando o conhecimento depende de circunstâncias ${ }^{13}$. Em medicina, a capacidade interpretativa é o raciocínio clínico e, conforme viemos discutindo, este difere da racionalidade da ciência que ela tanto idealiza. Não importa quão sólida seja a ciência ou quão precisa a tecnologia empregada, a clínica permanece uma prática interpretativa, conjetural $^{28}$. E15 exemplifica bem a posição de todos os entrevistados, convergindo com as observações de E16 e ampliando-as:

Minha cabeça tem uma metodologia própria. Eu começo pela anamnese. Eu tento pegar a história da forma mais minuciosa possível, relacionar qualquer dado que possa ser relevante. Eu demoro bastante com isso. Eu costumo fazer o exame físico da forma mais completa, independente dos sintomas. E aí, eu aprendi com meu mestre na medicina que a gente deve sempre lembrar grandes grupos de doenças: neoplásicas, infecciosas, inflamatórias... O que ele mostrava é que ele tinha OLHOS nas mãos. Porque ele conseguia com a mão dele, não só com a mão, obviamente, ouvido, olho [...], identificar coisas nas pessoas que muitas vezes passam despercebidas. Exames complementares só quando indicados de forma correta. Hoje eles estão sendo valorizados mais que o restante. Acho problemático. (grifo nosso)

A referência aos "olhos nas mãos" sintetiza bem o "o olho clínico" de Foucault ${ }^{24}$, certo olhar que vê, escuta, palpa e se 
aprofunda sempre em torno de três linhas: "o tempo próprio do corpo; a visibilidade do invisível e a intervenção técnica" (p. 251). O avanço da terceira se imbrica às outras e se tece a rede cujos fios são complicadas narrativas, contadas em palavras, gestos, silêncio, indícios, imagens, resultados de testes laboratoriais e mudanças nos corpos, todas convergindo num sentido que pode até ser provisório, mas é a base do raciocínio clínico impulsionador da ação médica ${ }^{27}$.

\section{CONSIDERAÇÕES FINAIS}

É inquestionável o quanto o papel das narrativas médicas vem sendo motivo de debates, publicações nas mais diversas revistas especializadas, livros escritos por pesquisadores voltados à divulgação de sua importância, cursos, simpósios e programas organizados em diversas faculdades de Medicina. Também é inegável a ênfase colocada na narrativa como ferramenta para o entendimento da doença por parte de quem a tem, para uma boa relação médico-paciente, para a educação e formação médica, incluindo-se, principalmente, questões relativas à ética.

No que tange à nossa pesquisa, a par de considerarmos todas essas proposições, a que mais nos interessou foi a do entendimento do processo narrativo como inerente ao raciocínio clínico fundamental à Semiologia Médica. Entretanto, todas as discussões acerca do tema fazem referência a uma "epistemologia narrativa", mas não se voltam especificamente à investigação do quanto a consciência de trabalhar em bases da narrativa, isto é, ordenando o que se vê e o que se escuta, dita quais exames complementares precisam ser feitos para corroborar hipóteses diagnósticas, que são os elementos constituintes do exercício do ofício.

Nessa direção, nossos entrevistados se mostraram impregnados pelo conhecimento médico e extremamente conscientes da importância da Semiologia e do desenvolvimento do raciocínio clínico, condição sine qua non para exercê-la. Prestes a terminar o Programa de Residência Médica em Pediatria, demonstram estar imbuídos de sua missão, posicionando-se como semiotas e pugnando pela experiência prática aliada à teoria como fulcrais ao atendimento de seus pacientes. Em nenhum deles ainda se manifestou a ilusão absoluta da utilização dos recursos tecnológicos como deslindadores neutros do estado de saúde e/ou de doença de seus pacientes. Em todos, a condução da prática clínica passa pelo ouvir e pelo observar. O "olhar clínico" se manifesta como o princípio do cuidar e permanece enaltecido como algo que se desenvolve, se treina, se melhora, se amplia ao longo da atividade médica. Só que ele não se refere somente ao palpar e ao visualizar, mas remete ao escutar e ao ordenar reflexivamente. Pode-se inferir que, no fundo e de certa forma, esse "olhar" ordena no tempo e no espaço os eventos constituintes do processo da saúde e da doença e o pesquisa narrativamente.

Escutar e também analisar o que ouvimos de nossos entrevistados nos propiciaram entender a não conscientização da narratologia como base epistemológica do saber médico e também nos permitiram constatar que eles a agenciam e a tomam como princípio do empreendimento semiológico, desenvolvendo, através dela, cada vez mais o raciocínio clínico.

\section{REFERÊNCIAS}

1. Guedes CR, Nogueira MI, Camargo Júnior KR. A subjetividade como anomalia: contribuições epistemológicas para a crítica do modelo biomédico. Ciênc Saúde Coletiva. 2006;11(4):1093-103.

2. Smith D. Diagnosis Goes Low Tech. The New York Times on Web [periódico na internet]. 2003 [acesso em 20 jan. 2010]. Disponível em: http://narrativemedicine. Org/ press/DiagnosisGoesLowTech

3. Cuminale N. A Médica do Dr. House. Veja [periódico na internet] 2010. [acesso em 29 nov. 2010]. Disponível em: http:/ /veja.abril.com.br/noticias/saude/saude-house-lisa-sanders-entrevista.

4. Davin S. Healthy viewing: the reception of medical narrativas. Sociology of Health \& Illness. 2003; 25(6):662-79.

5. Universidade de Lisboa. Colóquio Internacional de Medicina e Narrativa: Doença e Dialógo [online]. [acesso em 20 jan. 2011]. Disponível em http://www.ulices.org/eventos/coloquio-internacional-narrativa-e-medicina-doenca-e-dialogo.html

6. Villar MM, Cardoso MHCA. Residência médica em pediatria: no campo de prática. Cad Saúde Pública. 2002;18(1):329-39.

7. Canguilhem G. Escritos sobre medicina. Rio de Janeiro: Forense Universitária; 2005.

8. Camargo Júnior KR. A Biomedicina. Physis. 2005;15(suppl):177-201.

9. Carr D. Time, Narrative, and History. Bloomington: Indiana University Press; 1986.

10. Epstein J. Altered Conditions. Disease, Medicine and Storyteller. New York/London: Routledge; 1995.

11. Heath I. Following the story: continuity of care in general practice. In: Greenhalgh T, Hurwitz B, eds. Narrative Based Medicine: dialogue and discourse in clinical practice. London: BMJ Books; 1998. p. 83-92.

12. Castiel LD. a medida do possível...saúde, risco e tecnobiociências. Rio de Janeiro: Ed. Fiocruz; 1999. 
13. Montgomery K. How doctors think. Clinical Judgment and the Practice of Medicine. New York: Oxford University Press; 2006.

14. Hunter KM. Doctors' stories. The narrative structure of medical knowledge. Princeton: Princeton University Press; 1993.

15. Grossman E, Cardoso MHCA. As narrativas em medicina: contribuições à prática clínica e ao ensino médico. Rev Bras Educ Med. 2006;30(1):6-14.

16. Collins KMT, Onwuegbuzie AJ, Jiao QG. A Mixed Methods Investigation of Mixed Methods Sampling Designs in Social and Health Science Research . J Mixed Methods Research. 2007;1(3):267-29.

17. Nolla-Domenjó M. Formacion Continuada. El processo cognitivo y el aprendizage profesional. Educ Med. 2006;9(1):11-6.

18. Neves FF, Pazin-Filho P. Raciocínio clínico na sala de urgência. Temas de Ensino Médico. 2008; 41(3):339-46.

19. Minayo MCS. O Desafio do Conhecimento. Pesquisa Qualitativa em Saúde. São Paulo: hucitec; 2006.

20. Romeiro V. Semiologia Médica. Rio de Janeiro: Guanabara-Koogan; 1980.

21. Midão CMV, Ruiz-Moreno L. O Ensino da Semiologia nas Escolas Médicas do Estado do Rio de Janeiro. Rev Bras Educ Med. 2010;34(3):397-405.

22. Cardoso MHCA. História e Medicina: a Herança Arcaica de um Paradigma. Hist Ciência Saúde - Manguinhos. 2000;6(3):551-75.
23. Foucault M. O Nascimento da Clínica. Rio de Janeiro: Forense; 1994.

24. Favoreto $\mathrm{CAO}$, Camargo Júnior. KR. A Narrativa como Ferramenta para o Desenvolvimento da Prática Clínica. Interface Comun Saúde Educ. 2011;15(37):473-83.

25. Popper KR. A Lógica da Pesquisa Científica. São Paulo: Cultrix; 2000

26. Réa-Neto A. Raciocínio Clínico: o Processo de Decisão Diagnóstica e Terapêutica. Rev Assoc Med Bras. 1998;44(4):301-11.

27. Charon R. Narrative Medicine. Honoring the Stories of Illness. New York: Oxford University Press; 2006.

28. Ginzburg C. Sinais. Raízes de um Paradigma Indiciário. In: Mitos, Emblemas e Sinais. Morfologia e História. São Paulo: Companhia das Letras; 1989, p.143-79.

\section{CONTRIBUIÇÃO DOS AUTORES}

As autoras trabalharam juntas em todas as etapas de produção do manuscrito.

\section{CONFLITO DE INTERESSES}

Declarou não haver.

\section{ENDEREÇO PARA CORRESPONDÊNCIA}

Leda Amar de Aquino

Rua Presidente Alfonso Lopez, 20 - apto 601

Lagoa - Rio de Janeiro

CEP 22071-050 - RJ

E-mail: ledaaquino@alternex.com.br 